\title{
Harvest Maturity, Storage Temperature, and 1-MCP Application Frequency Alter Firmness Retention and Chlorophyll Fluorescence of 'Redchief Delicious' Apples
}

\author{
Nazir A. Mir, ${ }^{1}$ Erin Curell, Najma Khan, Melissa Whitaker, and Randolph M. Beaudry ${ }^{2}$ \\ Department of Horticulture, Michigan State University, East Lansing, MI 48824-1325
}

ADDITIONAL INDEX WORDs. Malus sylvestris var. domestica, 1-methylcyclopropene, ripening, climacteric, quality, food, preservation

\begin{abstract}
Fruit of 'Redchief Delicious' apple [Malus sylvestris (L) Mill. var.domestica (Borkh.) Mansf.] were harvested 1 week before the climacteric (harvest 1 ), at the onset of the climacteric (harvest 2), and 1 week after the onset of the climacteric (harvest 3). Fruit were stored at $0,5,10,15$, or $20^{\circ} \mathrm{C}$ and were treated with $0.7 \mu \mathrm{L} \cdot \mathrm{L}^{-1} 1$-MCP on a once-perweek, once-per-2-week, once-per-month, and once-per-year basis or were left nontreated. The initial 1-MCP treatment was at $20{ }^{\circ} \mathrm{C}$ and subsequent applications were at storage temperatures. The compound slowed softening at all temperatures relative to nontreated fruit, however as temperature decreased, the benefits of 1-MCP application became less pronounced. Effectiveness of 1-MCP declined slightly as harvest maturity increased. Efficacy of 1-MCP treatment increased with greater frequency of application at $5,10,15$, and $20^{\circ} \mathrm{C}$, but not at $0^{\circ} \mathrm{C}$. Fruit stored without refrigeration $\left(20^{\circ} \mathrm{C}\right)$ for more than 100 days did not soften significantly when treated once per week with 1-MCP. However, decay was a significant problem for treated and nontreated fruit stored at temperatures $>5{ }^{\circ} \mathrm{C} ; 1-\mathrm{MCP}$ application reduced, but did not prevent decay. Rate of decline in titratable acidity increased with storage temperature and 1-MCP had no significant effect on retarding the decline in acid content. Minimal (Fo) and maximal (Fm) chlorophyll fluorescence was altered markedly by 1-MCP application, but the ratio of $(\mathrm{Fm}-\mathrm{Fo}) / \mathrm{Fm}$ was only slightly affected. The most effective 1-MCP treatment frequency was once per week and, at all elevated temperatures $\left(5,10,15\right.$, and $\left.20{ }^{\circ} \mathrm{C}\right)$, slowed loss of firmness to a greater extent than refrigeration $\left(0^{\circ} \mathrm{C}\right)$ alone. Application of 1-MCP resulted in greater retention of firmness than controlled atmosphere $(\mathrm{CA})$ with $\mathrm{O}_{2}$ and $\mathrm{CO}_{2}$ at $1.5 \mathrm{kPa}$ and $3 \mathrm{kPa}$, respectively. Data suggest that 1-MCP application, has the potential to reduce reliance on refrigeration and CA storage for maintaining firmness of 'Redchief Delicious' apple, especially for relatively short storage durations ( $<50$ days) when fruit are harvested within a week of the ethylene climacteric. Chemical name used: 1-methylcyclopropene (1-MCP).
\end{abstract}

Ethylene is a gaseous plant hormone produced by all higher plants. Responses include defoliation, fruit abscission, flower abscission, degreening, fruit ripening, color (pigment) development, release of dormancy, stimulation of branching, adventitious root formation, flower induction, and promotion of fruit maturity (Abeles et al., 1992). Growth regulators can be used to regulate ethylene effects. These include ethylene releasing compounds such as (2-chloroethyl) phosphonic acid (Kays and Beaudry, 1987), materials that inhibit ethylene action such as silver ion (Cameron and Reid, 1981), and those that inhibit ethylene production such as 1-aminoethoxyvinylglycine (Yang and Hoffman, 1984). Commercial formulations of each of these materials are used widely in horticulture.

Of particular value in the storage of climacteric fruit are those techniques that reduce ethylene responses, thereby permitting some control over degradative processes associated with ripening and senescence. In fruit storage, cultural techniques used to minimize the effects of ethylene include low $\mathrm{O}_{2}$, high $\mathrm{CO}_{2}$, and reduced temperature (Abeles et al., 1992). Silver, while effective at preventing or slowing fruit ripening (Tucker and Brady, 1987),

Received for publication 2 Jan. 2001. Accepted for publication 7 May 2001 Research supported by the Project for Generating Research and Extension to meet Economic and Environmental Needs (GREEEN) and the Michigan State Horticultural Society. We thank Mahesh Rana and Chhatar Mehla, Department of Vegetable Crops, Haryana University, Hisar, India and Joan Runkle, Department of Horticulture, Michigan State University, for technical assistance. Mention of a trademark does not imply endorsement of the product. The cost of publishing this paper was defrayed in part by page charges. Under postal regulations, this paper must be hereby marked advertisement solely to indicate this fact.

${ }^{1}$ Former research associate. Currently director of research, EPL Technologies, Inc., 2 International Plaza, Philadelphia, PA 19113; e-mail: mirn@ @ilot.msu.edu. ${ }^{2}$ Associate professor and corresponding author; e-mail: beaudry@ pilot.msu.edu. is considered a heavy metal and is therefore relegated to nonfood applications. A relatively new growth regulator, 1-MCP, has been shown to have significant promise as an ethylene action inhibitor (Sisler and Blankenship, 1996; Sisler et al., 1996). Presently approved for use in ornamentals, 1-MCP is not yet approved for application on food crops by the U.S. Environmental Protection Agency.

$1-\mathrm{MCP}$, a cyclic olefin, is a vapor under physiological conditions and in its present formulation is produced by mixing a dilute aqueous buffer containing $\mathrm{KOH}$ and the parent compound EthylBloc (Floralife, Inc., Walterboro, S.C.), an $\alpha$-cyclodextrin encapsulation agent/1-MCP complex, to release the active gas. 1-MCP acts by inhibiting binding of the hormone, ethylene, to its receptor binding site (Serek et al., 1994). A single exposure to 1-MCP can temporarily render plant material insensitive to ethylene when applied at the $\mathrm{nL} \cdot \mathrm{L}^{-1}$ level and, at the concentrations needed for activity, 1MCP confers no disagreeable odor (Sisler and Blankenship, 1996). The compound was found to reduce ethylene-related responses in apple (Fan et al., 1999; Rupasinghe et al., 2000; Watkins et al., 2000), banana (Musa ×paradisica L.) (Golding et al., 1998), broccoli [Brassica oleracea L. (Botrytis group)] (Ku and Wills, 1999a), carrot (Daucus carota L.) (Fan and Mattheis, 1999), lettuce (Latuca sativa L.) (Fan and Mattheis, 1999), tomato (Lycopersicon esculentum Mill.) (Mir et al., 1999), and strawberry [Fragaria $\times$ ananassa Duchesne] (Ku and Wills, 1999b).

Published studies of apple responses to 1-MCP suggest that a single postharvest application could prevent ripening for an extended period at ambient $\left(24^{\circ} \mathrm{C}\right)$ temperature relative to nontreated controls (Fan et al., 1999). This finding suggests that some aspects of fruit quality such as fruit firmness and titratable acidity could be maintained for a short period without refrigera- 
tion. In addition, studies on tomato suggest that multiple applications may prove more effective than a single application (Mir et al., 1999). If apples respond to multiple applications in a fashion similar to tomatoes, the possibility is raised that storage at elevated temperatures could be extended relative to a single application. The implication is that 1-MCP could reduce reliance on refrigeration. In a similar vein, reliance on low $\mathrm{O}_{2}$ and elevated $\mathrm{CO}_{2}$ conditions of controlled atmosphere (CA) storage could be reduced. In fact, data from Watkins et al. (2000) suggest that 1-MCP application can result in fruit of some apple cultivars retaining firmness at levels similar to CA-stored fruit for several months.

The potential for multiple exposures or continuous exposure of apples to 1-MCP has not been thoroughly evaluated. Most studies have involved application of a single dose of 1-MCP at the initiation of the storage period. In addition, the interplay of application temperature, harvest maturity, and application frequency is not known for apple. In this study, we attempted to extend previous findings by evaluating 1-MCP efficacy in relation to 1) fruit maturity at harvest, 2) repeated or multiple exposures, and 3) storage temperature. Response of 'Redchief Delicious' apples, harvested at three stages of maturity to 1-MCP applied at four different frequencies during storage at 0, 5, 10, 15, and $20{ }^{\circ} \mathrm{C}$ was examined. Central to our goals, we wished to determine if successful apple storage can be achieved at temperatures significantly above $0{ }^{\circ} \mathrm{C}$ solely by application of 1-MCP. The capacity of 1-MCP treatment to retain fruit firmness relative to storage in air and CA was also evaluated.

\section{Materials and Methods}

Plant material. 'Redchief Delicious' apples were harvested 1 week before the climacteric (harvest 1), at the onset of the climacteric (harvest 2), and 1 week after the onset of the climacteric (harvest 3 ) as determined by the average internal ethylene level (IEC) and starch index of ten representative fruit. Average IEC was $1.8 \mu \mathrm{L} \cdot \mathrm{L}^{-1}\left(50 \%\right.$ having an IEC $\left.<0.2 \mu \mathrm{L} \cdot \mathrm{L}^{-1}\right), 8.3 \mu \mathrm{L} \cdot \mathrm{L}^{-1}(90 \%$ having an IEC $\left.>0.2 \mu \mathrm{L} \cdot \mathrm{L}^{-1}\right)$, and $41.4 \mu \mathrm{L} \cdot \mathrm{L}^{-1}(100 \%$ having an IEC $\left.>0.2 \mu \mathrm{L} \cdot \mathrm{L}^{-1}\right)$ for harvests 1,2 , and 3 , respectively. Respective starch indices were 2.2, 2.9, and 4.6. Fruit were placed into plastic mesh bags (60 fruit/bag) and three bags were placed in airtight, plastic 113-L barrels.

1-MCP AND STORAGE TREATMENTS. After fruit were sealed in the plastic barrels, concentrated 1-MCP gas was injected into the barrel to bring the final gas concentration to $0.7 \mu \mathrm{L} \cdot \mathrm{L}^{-1}$, which was expected to be sufficient to saturate the response to 1-MCP (Fan et al., 1999). To create the concentrated 1-MCP gas, $2.5 \mathrm{~g}$ of EthylBloc was placed in a 1-L glass jar. The jar was sealed with a lid fitted with a rubber serum stopper. Fifty milliliters of dilute $\mathrm{KOH}$ buffer was added to the jar by injecting the buffer solution through the lid. The 1-MCP was allowed to release for at least 3 h. Fifty milliliters of the headspace in the glass jar was removed using a $50-\mathrm{mL}$ syringe and injected into the sealed barrels. As each $50 \mathrm{~mL}$ volume of gas was removed, $50 \mathrm{~mL}$ of water was injected into the jar, maintaining a slight positive pressure in the container and preventing dilution of 1-MCP in the jar headspace.

All 1-MCP-treated fruit received an initial treatment at ambient temperature $\left(\approx 20^{\circ} \mathrm{C}\right)$ and subsequent treatments were at the indicated storage temperature. Control fruit were also sealed in chambers, but were left nontreated. For the initial treatment, fruit were left in the treatment barrels for $16 \mathrm{~h}$. After this, the mesh bags containing the fruit were removed from the treatment chambers and placed in barrels in controlled temperature chambers held at
$0,5,10,15$, or $20^{\circ} \mathrm{C}$. Fruit were arranged such that one mesh bag from each of the three harvests was in each barrel. Fruit were given treated with $1-\mathrm{MCP}$ at $0.7 \mu \mathrm{L} \cdot \mathrm{L}^{-1}$ on a once-per-week (1/ week), once-per- 2 week ( $1 / 2$ weeks), once-per-month ( $1 /$ month), and once-per-year (1/year) basis or were left nontreated. The fruit given the 1/year treatment did not receive any additional exposures to 1-MCP beyond the initial treatment. In all, there were 75 harvest/temperature/frequency combinations, there were two replications of each combination.

The barrels were flushed continuously with air at a rate of $\approx 200$ $\mathrm{mL} \cdot \mathrm{min}^{-1}$ except when the $1-\mathrm{MCP}$ was applied, at which time the barrels were sealed with stoppers and 1-MCP was administered as described previously. Treatments with 1-MCP subsequent to the first treatment were all given at the storage treatment temperature. Paper bags containing $100 \mathrm{~g}$ of hydrated lime were included in each barrel to minimize $\mathrm{CO}_{2}$ accumulation. During storage, 10 fruit (five from each replication) per treatment combination were removed at intervals ranging from 7 to $40 \mathrm{~d}$, held at $22{ }^{\circ} \mathrm{C}$ overnight, and evaluated for firmness and chlorophyll fluorescence. At 3 months storage, titratable acidity was determined and an additional 10 fruit (five per replication) were assessed for firmness after an additional holding period of $7 \mathrm{~d}$ at room temperature. At 6 months storage, an additional 10 fruit (five per replication) were removed from the $0{ }^{\circ} \mathrm{C}$ air and 1 /week treatments and were assessed for firmness $1 \mathrm{~d}$ after removal from storage and after $7 \mathrm{~d}$ at room temperature. On each assay date, decaying fruit were removed from the barrels. When the last fruit were removed from a mesh bag, the total number of assayed fruit was subtracted from the initial number of fruit (60) to calculate the number of fruit discarded due to decay.

In addition to the air storage treatments, two replicates of 20 fruit from each harvest were placed in CA storage $\left(1.5 \% \mathrm{O}_{2}\right.$ and $3 \% \mathrm{CO}_{2}$ ) at $0{ }^{\circ} \mathrm{C}$ and held for 6 months. Fruit were ventilated at a rate of $30 \mathrm{~mL} \cdot \mathrm{min}^{-1}$. At the end of this storage period, fruit were held overnight at $22^{\circ} \mathrm{C}$ and 10 fruit were evaluated for firmness. Fruit firmness was assessed on the remaining 10 fruit after holding for $7 \mathrm{~d}$ at room temperature. A completely randomized experimental design was used. Data were subjected analysis of variance procedures and mean separated by least squares analysis.

Assays. For harvest maturity, IEC was determined by withdrawing a 1-mL gas sample from the interior of apples and subjecting the gas sample to gas chromatographic analysis. The gas chromatograph (GC) (Carle Series 400 AGC; Hach Co., Loveland, Colo.) was fitted with a 6-m-long, 2-mm-i.d. stainlesssteel column packed with activated alumina and detection was via a flame ionization detector. The ethylene detection limit was $\approx 0.005 \mu \mathrm{L} \cdot \mathrm{L}^{-1}$. Ethylene concentrations were calculated relative to a certified standard (Matheson Gas Products, Chicago, Ill.) with a concentration of $0.979 \mu \mathrm{L} \cdot \mathrm{L}^{-1}$.

The starch index at harvest was determined by cutting fruit in half through the seed cavity along the plane perpendicular to the longitudinal axis. One of the cut surfaces was dipped into an iodine solution containing $10 \mathrm{~g} \mathrm{KI}$ and $40 \mathrm{~g} \mathrm{I}_{2}$ per $4 \mathrm{~L}$ of water. Color development was allowed to proceed for $\approx 5 \mathrm{~min}$. Starch index was determined by comparison to the Cornell Starch Chart (Blanpied and Silsby, 1992) where $1=$ black staining across the entire cut surface and $8=$ no staining.

Firmness of fruit was measured manually using a drill-standmounted Effegi penetrometer (FT-327; McCormick Fruit Tree Inc., Yakima, Wash.) fitted with an 11-mm-diameter probe. The penetrometer was calibrated at $53.4 \mathrm{~N}(12 \mathrm{lb})$ using a top-loading balance. Two skin discs $(\approx 2.5 \mathrm{~cm}$ in diameter) were removed 

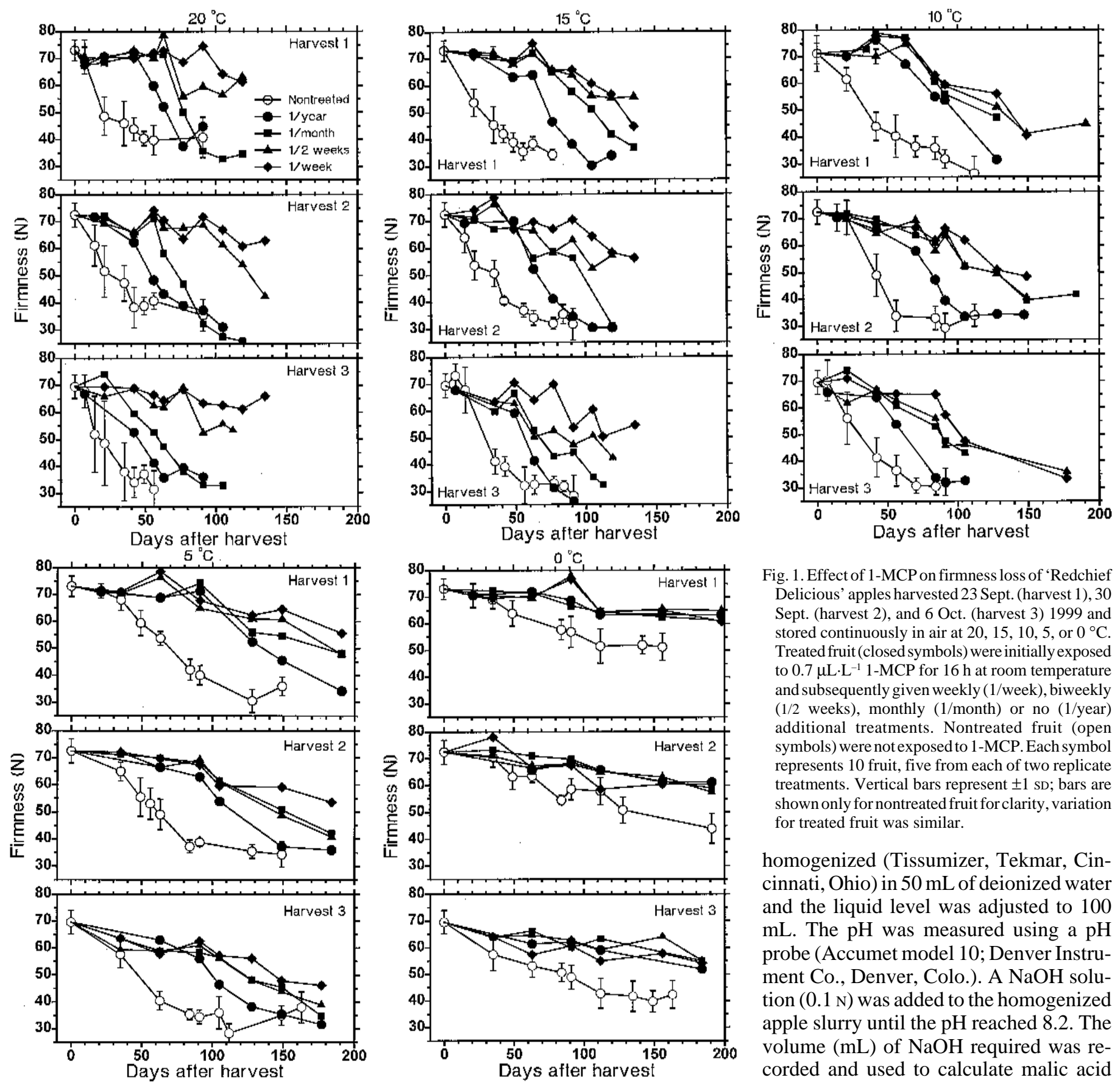

Fig. 1. Effect of 1-MCP on firmness loss of 'Redchief Delicious' apples harvested 23 Sept. (harvest 1), 30 Sept. (harvest 2), and 6 Oct. (harvest 3) 1999 and stored continuously in air at $20,15,10,5$, or $0{ }^{\circ} \mathrm{C}$. Treated fruit (closed symbols) were initially exposed to $0.7 \mu \mathrm{L} \cdot \mathrm{L}^{-1} 1-\mathrm{MCP}$ for $16 \mathrm{~h}$ at room temperature and subsequently given weekly (1/week), biweekly (1/2 weeks), monthly ( $1 /$ month) or no (1/year) additional treatments. Nontreated fruit (open symbols) were not exposed to 1-MCP. Each symbol represents 10 fruit, five from each of two replicate treatments. Vertical bars represent \pm 1 sD; bars are shown only for nontreated fruit for clarity, variation for treated fruit was similar.

homogenized (Tissumizer, Tekmar, Cincinnati, Ohio) in $50 \mathrm{~mL}$ of deionized water and the liquid level was adjusted to 100 $\mathrm{mL}$. The $\mathrm{pH}$ was measured using a $\mathrm{pH}$ probe (Accumet model 10; Denver Instrument Co., Denver, Colo.). A NaOH solution $(0.1 \mathrm{~N})$ was added to the homogenized apple slurry until the $\mathrm{pH}$ reached 8.2 . The volume $(\mathrm{mL})$ of $\mathrm{NaOH}$ required was recorded and used to calculate malic acid equivalents using the relationship of 0.0067

from opposite sides of each fruit. The penetrometer probe was pressed into the tissue of the cut surface to a depth of 8 to $9 \mathrm{~mm}$ in a single smooth motion requiring $\approx 1 \mathrm{~s}$. Data were recorded as pounds and converted to Newtons by multiplying by $4.45 \mathrm{~N} / \mathrm{lb}$. The time required for control fruit to soften to $53.4 \mathrm{~N}(12 \mathrm{lb})$ was recorded. The Washington tree fruit industry uses $12 \mathrm{lb}$ as a threshold for packing some of its fresh apples.

Chlorophyll fluorescence was measured on the surface of the fruit using a fluorometer (OS500; OptiSciences, Tyngsboro, Mass.) as described by Mir et al. (1998). Data collected were minimal $(\mathrm{Fo})$ and maximal fluorescence $(\mathrm{Fm})$. From these data the ratio $(\mathrm{Fm}-\mathrm{Fo}) / \mathrm{Fm}$, otherwise referred to as $\mathrm{Fv} / \mathrm{Fm}$, was calculated to estimate photochemical quantum efficiency.

Titratable acidity and tissue $\mathrm{pH}$ were measured for fruit of all treatments after 3 months. About $10 \mathrm{~g}$ of apple tissue was g malic acid titrated per $\mathrm{mL} \mathrm{NaOH}$ solution and dividing by the tissue weight. Data are presented as percentage malic acid on a fresh weight basis.

The 1-MCP concentration was verified using gas chromatography using 1-butene as a standard. The GC (Carle Series 100 AGC) was fitted with a 6-m-long, 2-mm-i.d. stainlesssteel column packed with Chromosorb 103, 60/80 mesh and detection was via a flame ionization detector. The 1-butene standard concentration was $10 \mu \mathrm{L} \cdot \mathrm{L}^{-1}$ and was made by injecting $43 \mu \mathrm{L}$ of pure 1-butene (Matheson Gas Products, Chicago, Ill.) into a 4.3-L glass flask fitted with specially made ground glass stopper containing a gas-tight sampling port (Mininert valve; Altech Associates, Inc., Deerfield, Ill.). The retention times of 1-butene and 1-MCP were $\approx 1.3$ and 1.5 min, respectively. 


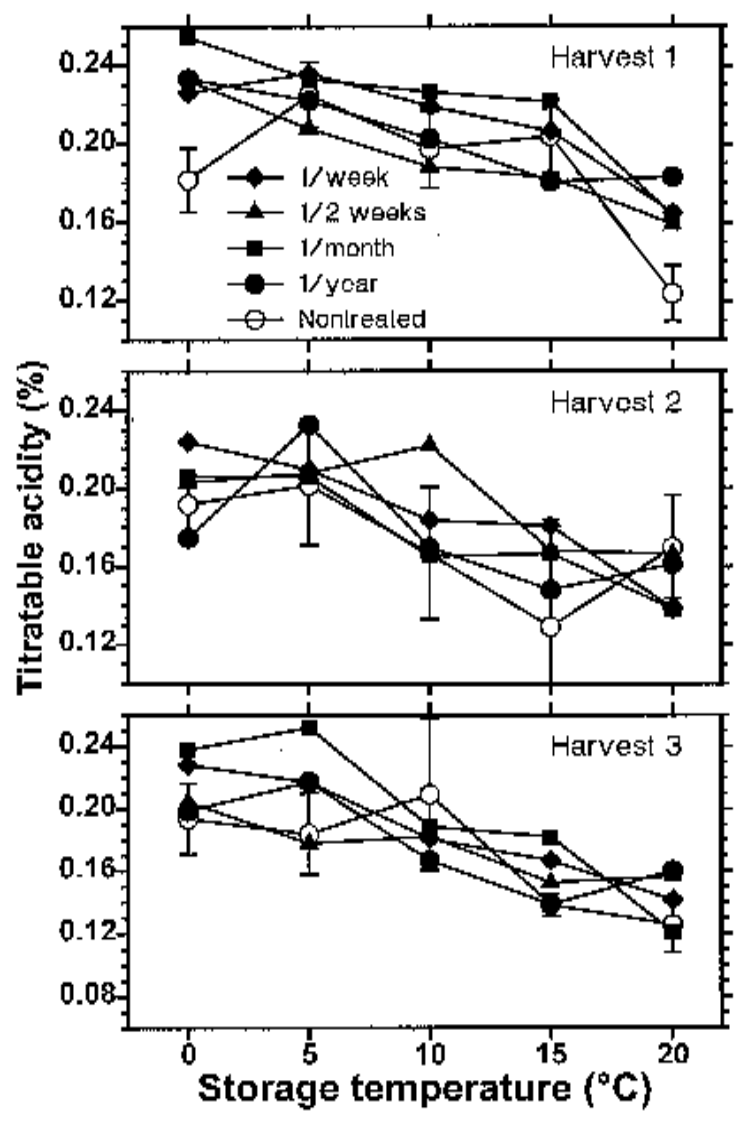

Fig. 2. Effect of 1-MCP on the titratable acidity (percentage malic acid) of 'Redchief Delicious' apple puree for fruit harvested 23 Sept. (harvest 1), 30 Sept. (harvest 2), and 6 Oct. (harvest 3) 1999 and stored 3 months in air at the indicated temperature. Treated fruit (closed symbols) were initially exposed to $0.7 \mu \mathrm{L} \cdot \mathrm{L}^{-1} 1-\mathrm{MCP}$ for $16 \mathrm{~h}$ at room temperature and subsequently given weekly (1/week), biweekly (1/2 weeks), monthly (1/month), or no (1/year) additional treatments. Nontreated fruit (open symbols) were not exposed to 1-MCP. Each symbol represents 10 fruit, five from each of two replicate treatments. Vertical bars represent $\pm 1 \mathrm{SD}$; bars are shown only for nontreated fruit for clarity, variation for treated fruit was similar.

\section{Results}

At harvest, fruit of all three harvests had a firmness of $\approx 71$ to 73 $\mathrm{N}(16$ to $16.5 \mathrm{lb})$. As storage temperature increased, the rate of softening of nontreated fruit increased (Fig. 1). The time required for control fruit to soften to $53.4 \mathrm{~N}(12 \mathrm{lb})$, was $\approx 18,25,35,55$, and 105 d at $20,15,10,5$, and $0^{\circ} \mathrm{C}$, respectively. Firmness of nontreated fruit declined more rapidly than 1-MCP-treated fruit at all application frequency/temperature combinations. At $0^{\circ} \mathrm{C}$, there did not appear to be any effect of the frequency of application of 1-MCP on fruit softening. Treated and nontreated fruit tended to soften more rapidly as harvest was delayed. For fruit held at $5^{\circ} \mathrm{C}$, there was some separation of 1-MCP treatments, with the fruit treated 1/year softening the most rapidly and those treated 1/week the least rapidly. Similar results were found for the other storage temperatures, with the separation of 1-MCP frequencies becoming more pronounced as temperature increased. For the 1/week 1-MCP treatment, softening was more rapid at $10^{\circ} \mathrm{C}$ than at 0 or $20^{\circ} \mathrm{C}$.

Since fruit response to the 1-MCP treatment was a function of temperature and 1-MCP application frequency, the interval between sampling dates was adjusted as the study continued to help optimize depiction of responses. As a result, some treatments were depleted of fruit sooner than others (Fig. 1). Loss of fruit to decay also reduced fruit numbers, further altering the period over which data were collected for the various treatment combinations. Although decay data were not recorded during the experiment, we calculated that $10 \%$ to $40 \%$ of the fruit stored at $20{ }^{\circ} \mathrm{C}$ were lost to decay by completion of the study. More fruit were lost to decay in the control chambers than in the 1-MCP treatments, especially at higher treatment frequencies (data not presented). No injury that could be traced to 1-MCP application was observed on any of the fruit.

Titratable acidity of fruit stored 3 months decreased with increasing storage temperature in a relatively linear fashion (Fig. 2 ). There was no effect of 1-MCP treatment or treatment frequency on titratable acidity and fruit of all three harvest maturities behaved similarly. The $\mathrm{pH}$ of the fruit increased linearly with temperature and there was no effect of 1-MCP or harvest maturity (data not presented).

Chlorophyll fluorescence was markedly affected by $1-\mathrm{MCP}$ application for fruit stored at $20^{\circ} \mathrm{C}$, but not for fruit stored at $0{ }^{\circ} \mathrm{C}$ (Fig. 3). At $20^{\circ} \mathrm{C}$, minimal fluorescence (Fo) tended to be lowest throughout storage for the nontreated fruit and higher for 1-MCPtreated fruit. As storage duration increased, Fo increased for those fruit exposed to 1-MCP at frequencies of 1/2 weeks or $1 /$ week. Maximal fluorescence (Fm) was also lowest for the nontreated fruit throughout storage at $20^{\circ} \mathrm{C}$. For $1 /$ year- and $1 /$ month-treated fruit, Fm declined with increasing storage duration. Fm of fruit treated $1 / 2$ weeks or $1 /$ week remained relatively stable throughout storage. Effect of 1-MCP on chlorophyll fluorescence at lower temperatures diminished as temperature declined (data not presented). Despite the strong influence of 1-MCP on Fo and Fm at $20^{\circ} \mathrm{C}$, the effect of $1-\mathrm{MCP}$ on the quantum efficiency ratio $\mathrm{Fv} /$ Fm was minimal (Fig. 4). The most effective 1-MCP treatment (1/ week) resulted in only a slight elevation in $\mathrm{Fv} / \mathrm{Fm}$ relative to controls during the later portion of storage. At $0{ }^{\circ} \mathrm{C}$ the rate of decline in $\mathrm{Fv} / \mathrm{Fm}$ was slower than at $20{ }^{\circ} \mathrm{C}$, but the $1-\mathrm{MCP}$ treatment had little effect. At temperatures between 0 and $20^{\circ} \mathrm{C}$, the rate of decline in $\mathrm{Fv} / \mathrm{Fm}$ was intermediate and there was no clear effect of 1-MCP (data not presented).

The firmness of nontreated fruit stored in air for 6 months declined from $\approx 73 \mathrm{~N}$ at harvest to $44 \mathrm{~N}$ (Fig. 5). There was a significant effect of storage treatment. Those fruit held in CA storage for 6 months were firmer than nontreated air-stored fruit, averaging $55 \mathrm{~N}$. Fruit treated with 1-MCP on a 1/week basis, but held in air for 6 months were firmer than nontreated air- or CAstored fruit.

\section{Discussion}

The effectiveness of 1-MCP in preventing apple softening is consistent with previously published reports (Fan et al., 1999; Rupasinghe et al., 2000; Watkins et al., 2000).

As reported by Fan et al. (1999), firmness of 'Delicious' fruit can be maintained at elevated temperatures $\left(24^{\circ} \mathrm{C}\right)$ for extended periods by even a single application of 1-MCP. Our data demonstrate that 1-MCP effectiveness at elevated temperatures can be improved by frequent applications. The improved effectiveness of increased frequency of application for all three harvest maturities at temperatures of $\geq 5{ }^{\circ} \mathrm{C}$ suggest that performance of 1MCP could be further enhanced by continuous exposure to 1MCP. Indeed, continuous exposure of tomato fruit appears to completely arrest color development and ripening in tomato fruit (Mir et al., unpublished).

The merits of fruit storage at elevated temperatures, even for 

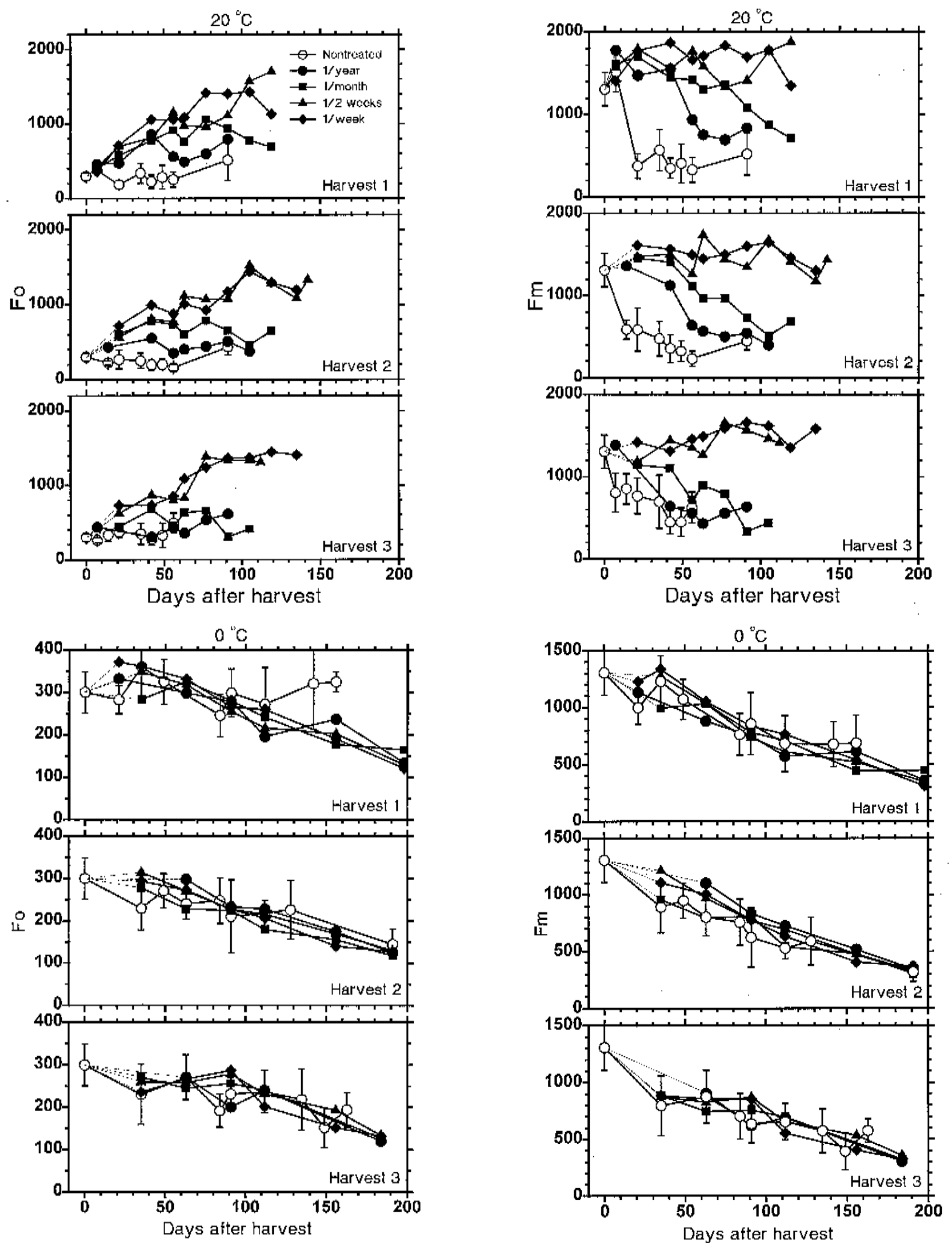

Fig. 3. Effect of 1-MCP on the minimal chlorophyll fluorescence (Fo) and maximal fluorescence (Fm) of 'Redchief Delicious' apples harvested 23 Sept. (harvest 1), 30 Sept. (harvest 2), and 6 Oct. (harvest 3) 1999 and stored continuously in air at 20 of $0{ }^{\circ} \mathrm{C}$. Treated fruit (closed symbols) were initially exposed to $0.7 \mu \mathrm{L} \cdot \mathrm{L}^{-1} 1$ MCP for $16 \mathrm{~h}$ at room temperature and subsequently given weekly (1/week), biweekly (1/2 weeks), monthly (1/month), or no (1/year) additional treatments. Nontreated fruit (open symbols) were not exposed to 1-MCP. Each data point represents 10 fruit, five from each of two replicate treatments. Vertical bars represent $\pm 1 \mathrm{SD}$; bars are shown only for nontreated fruit for clarity, variation for treated fruit was similar. 


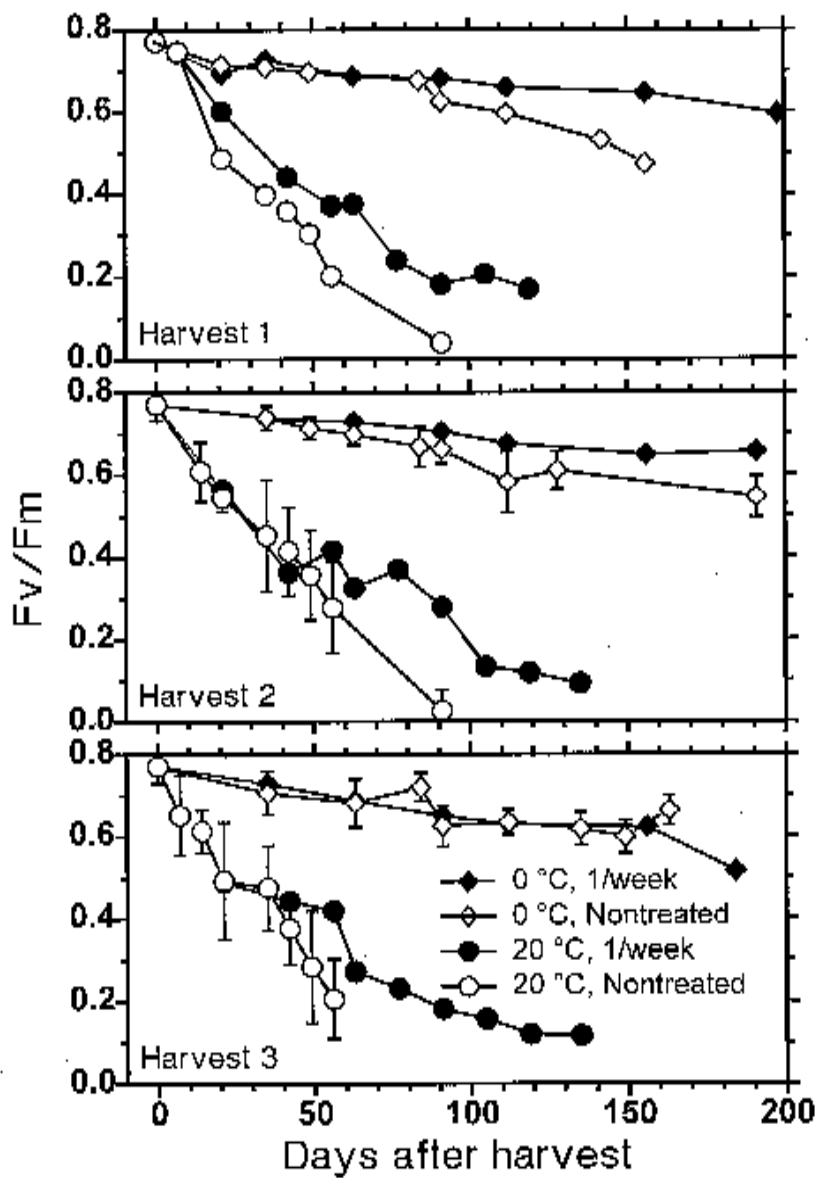

Fig. 4. Effect of 1-MCP on chlorophyll fluorescence (Fv/Fm) as a measure of photochemical quantum efficiency of 'Redchief Delicious' apples harvested 23 Sept. (harvest 1), 30 Sept. (harvest 2), and 6 Oct. (harvest 3) 1999 and held continuously in air at 0 or $20^{\circ} \mathrm{C}$. Treated fruit (closed symbols) were initially exposed to $0.7 \mu \mathrm{L} \cdot \mathrm{L}^{-1} 1-\mathrm{MCP}$ for $16 \mathrm{~h}$ at room temperature and subsequently given weekly (1/week) additional treatments. Nontreated fruit (open symbols) were not exposed to 1-MCP. Each symbol represents 10 fruit, five from each of two replicate treatments. Vertical bars represent \pm 1 SD; bars are shown only for nontreated fruit for clarity, variation for treated fruits was similar.

short storage durations, would include reduced inputs and possibly reduced costs to the storage operator. 'Delicious' apples are typically stored at $0{ }^{\circ} \mathrm{C}$. In this study, when the results in Fig. 1 were combined in such a way that the results of the refrigeration alone $(0$ ${ }^{\circ} \mathrm{C}$ ) could be compared with data for $1 /$ week treatments for storage temperatures of 5 to $20^{\circ} \mathrm{C}$, the data permit comparison of a standard storage technique with storage regimes requiring reduced levels of refrigeration (Fig. 6). It was apparent that 1-MCP maintained or enhanced firmness retention in each case. This suggests that 1-MCP application may permit a reduction in the reliance on refrigeration for apple storage.

The interplay between temperature and frequency of 1-MCP treatment in retarding fruit softening may bear additional scrutiny. If 1-MCP and reduced temperature both act to reduce the rate of ethylene responses, it would follow that the performance of 1-MCP in retarding firmness loss may increase as treatment temperature declines. In this study, one would expect, for instance, that the effect of the $1 /$ week treatment would be superior at $10^{\circ} \mathrm{C}$ in comparison to $20{ }^{\circ} \mathrm{C}$. However, the reverse was true, suggesting that the effectiveness of a given concentration of 1-MCP is reduced as treatment temperature declines. This relationship between temperature and the effectiveness of 1-MCP applications in apple have been further investigated by Mir and Beaudry (2001). It is possible that the affinity of the ethylene binding site for 1-MCP decreases as temperature declines. The concentration used in this study, 0.7 $\mu \mathrm{L} \cdot \mathrm{L}^{-1}$, is near the level needed to saturate 1-MCP response in apples treated at $20^{\circ} \mathrm{C}$ (Rupasinghe et al., 2000). If binding site affinity declines as temperature decreases, the concentration needed to achieve maximal firmness retention may increase. A reduction in effectiveness of the $1 /$ week $1-\mathrm{MCP}$ treatment at $10^{\circ} \mathrm{C}$ might be the reason that firmness loss at this temperature to be nearly as rapid as at $20^{\circ} \mathrm{C}$.

The effect of 1-MCP on ripening parameters such as starch degradation, sugar accumulation, and preservation of titratable acidity, is not as dramatic as its effect on firmness (Fan et al., 1999; Watkins et al., 2000). In this study, improvement of acidity retention by 1-MCP through maintenance of $\mathrm{pH}$ or titratable acidity, was not discernible. These data suggest there are several parameters used as physiological measures of ripeness or maturity that are not tightly linked with ethylene biology. This may have important implications on fruit quality. In the case of apple, acidity contributes a significant portion of taste quality (Jobling, 1993). Since storage at elevated temperatures permits acidity loss to occur at rates comparable to nontreated fruit, it is possible that 1-MCP treated fruit held at elevated temperatures, despite their firmness, may develop an insipid taste after extended storage. The impact of 1-MCP on aroma has been measured (Rupasinghe et al., 2000). The compound induces a profound reduction in aroma production at concentrations $>1 \mu \mathrm{L} \cdot \mathrm{L}^{-1}$. Thus, flavor may be seriously compromised by $1-\mathrm{MCP}$ application.

In addition to the problem posed by acidity loss, the extensive decay encountered in the 10,15 , and $20^{\circ} \mathrm{C}$ treatments indicates that the limiting factor for storage at elevated temperatures is shifted from softening to decay development. Since no form of decay control was imposed in this study, it is possible that decay may not be as great a limitation when fungicides or other decay control techniques are employed.

A loss in greenness and an increase in the yellow coloration of apples is often associated with ripening. Indeed, maintenance of Fm by the more frequent applications of 1-MCP suggests that chlorophyll content was little reduced during the storage of these fruit and that ethylene plays a major role in the degradation of chlorophyll.

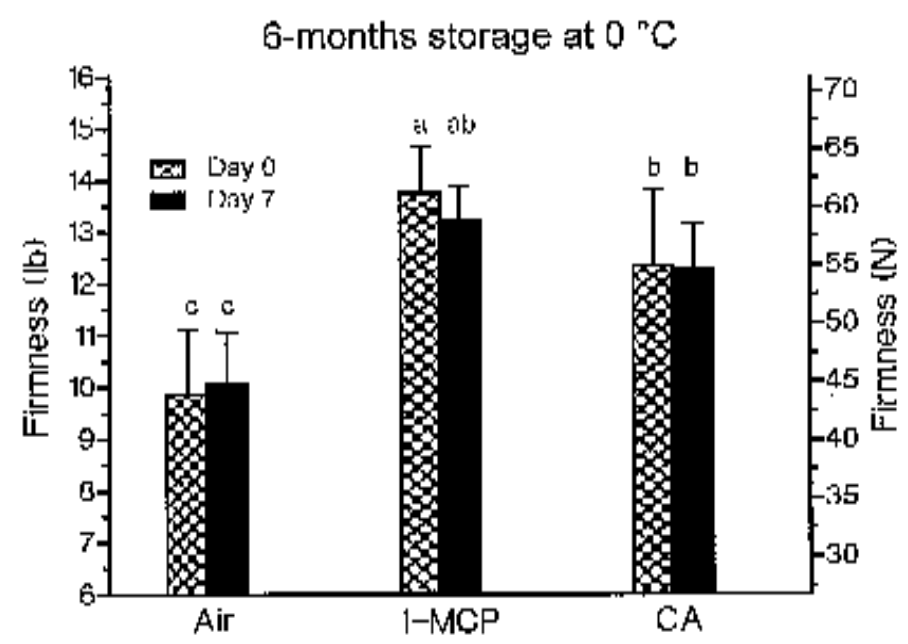

Fig. 5. Effect of air storage at $0{ }^{\circ} \mathrm{C}$ (Air), air storage at $0{ }^{\circ} \mathrm{C}$ with weekly 0.7 $\mu \mathrm{L} \cdot \mathrm{L}^{-1} 1-\mathrm{MCP}$ treatments (1-MCP), and CA storage at $0{ }^{\circ} \mathrm{C}, 1.5 \mathrm{kPa} \mathrm{O}$, and $3 \mathrm{kPa} \mathrm{CO} \mathrm{CO}_{2}(\mathrm{CA})$ on 'Redchief Delicious' fruit firmness after 6 months of storage and after an additional $7 \mathrm{~d}$ at $20^{\circ} \mathrm{C}$. Each value represents an average of 10 fruit from each of three harvests. Vertical lines represent 1 SD. The LSD ( $p=$ 0.05 ) was $4.3 \mathrm{~N}$; firmness values are significantly different if letters above vertical lines differ. 


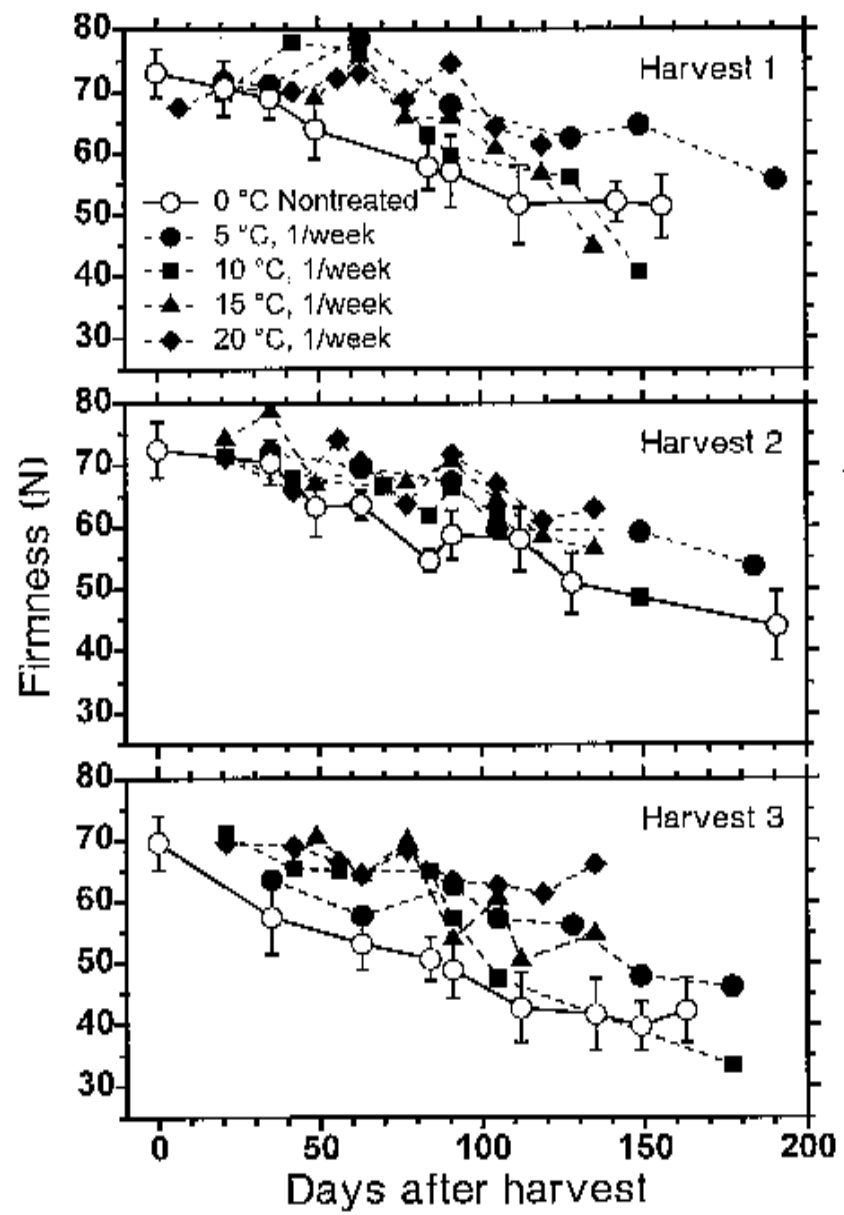

Fig. 6. Comparison of firmness of 'Redchief Delicious' apples harvested 23 Sept. (harvest 1), 30 Sept. (harvest 2), and 6 Oct. (harvest 3) 1999 and held in air storage at $0{ }^{\circ} \mathrm{C}$ without 1 -MCP treatment (open symbols) with those treated weekly with $0.7 \mu \mathrm{L} \cdot \mathrm{L}^{-1} 1-\mathrm{MCP}$ and stored at temperatures $>0{ }^{\circ} \mathrm{C}$ (solid symbols). Each symbol represents 10 fruit, five from each of two replicate treatments. Vertical bars represent $\pm 1 \mathrm{sD}$; bars are shown only for nontreated fruit for clarity, variation for treated fruit was similar.

This is supported by the observation that the background color of 1MCP-treated fruit was more green than control fruit (data not presented). Despite the enhancement of chlorophyll retention, the rise in Fo and the concomitant decline in quantum efficiency of 1MCP-treated fruit suggest a significant portion of the loss in chloroplast function occurs largely independent of ethylene action.

That 1-MCP effectively prevented softening at all temperatures relative to nontreated controls suggests it has the potential to have a major impact on the cultural aspects of apple storage. However, storage of 1-MCP-treated apples at elevated temperatures may negatively impact some aspects of fruit flavor and require some means of controlling decay in storage. In contrast, 1-MCP may very well complement and/or reduce the reliance on CA storage and has the potential to permit storage for short to intermediate durations ( 1 to 3 months) at elevated temperatures.

\section{Literature Cited}

Abeles, F.B., P.W. Morgan, and M.E. Saltveit, Jr. 1992. Ethylene in plant biology. 2nd ed. Academic Press, San Diego.

Blanpied, G.D. and K. Silsby. 1992. Predicting harvest date windows for apples. Info. Bul. 221. Cornell Univ., Ithaca, N.Y.

Cameron, A. and M. Reid. 1981. The use of silver thiosulfate anionic complex as a foliar spray to prevent flower abscission in zygocactus. HortScience 16:167-174.

Fan, X., S. Blankenship, and J. Mattheis. 1999. 1-Methylcyclopropene inhibits apple ripening. J. Amer. Soc. Hort. Sci. 124:690-695.

Fan, X. and J. Mattheis. 1999. 1-Methylcyclopropene prevents development of ethylene-promoted postharvest physiological disorders of carrot, broccoli, and lettuce. HortScience 34:510 (abstr.).

Golding, J.B., D. Shearer, S.G. Wyllie, and W.B. McGlasson. 1998. Application of 1-MCP and propylene to identify ethylene-dependent ripening processes in mature banana fruit. Postharvest Biol. Technol. 14:127-132.

Jobling, J. 1993 How maturity affects the quality of new cultivars of apples. PhD diss., Univ. of Western Sydney, Richmond, N.S.W., Australia.

Kays, S. and R.M. Beaudry. 1987. Techniques for inducing ethylene effects. Acta Hort. 201:77-116.

Ku, V.V.V. and R.B.H. Wills. 1999a. Effect of 1-methylcyclopropene on the storage life of broccoli. Postharvest Biol. Technol. 17:127132.

Ku, V.V.V. and R.B.H. Wills. 1999b. 1-Methylcyclopropene can differentially affect the postharvest life of strawberries exposed to ethylene. HortScience 34:5119-120.

Mir, N.A. and R.M. Beaudry. 2001. Use of 1-MCP to reduce the requirement for refrigeration in the storage of apple fruit. Acta Hort. (in press).

Mir N.A., N. Khan, and R.M. Beaudry. 1999. 1-Methylcyclopropene extends shelf life of tomato at all stages of maturity. HortScience 34:538 (abstr.).

Mir, N.A., M. Wendorf, R. Perez, and R.M. Beaudry. 1998. Chlorophyll fluorescence is affected by some superficial defects in stored apple. J. Hort. Sci. Biotechnol. 73:846-850.

Rupasinghe, H.P.V., D.P. Murr, G. Paliyath, and L. Skog. 2000. Inhibitory effect of 1-MCP on ripening and superficial scald development in 'McIntosh' and 'Delicious' apples. J. Hort. Sci. Biotechnol. 75:271-276.

Serek, M., E.C. Sisler, and M.S. Reid. 1994. A volatile ethylene inhibitor improves the postharvest life of potted roses. J. Amer. Soc. Hort. Sci. 119:572-577.

Sisler, E. and S. Blankenship. 1996. Method of counteracting an ethylene response in plants. U.S. Patent No. 5,518,988 (21 May 1996). U.S. Patent and Trademark Office, Wash. D.C.

Sisler, E.C., E. Dupille, and M. Serek. 1996. Effect of 1methylcyclopropene and methylenecyclopropane on ethylene binding and ethylene action on cut carnations. Plant Growth Regulat. 18:79-86.

Tucker, G.A. and C.J. Brady. 1987. Silver ions interrupt tomato fruit ripening. J. Plant Physiol. 127:165-169.

Watkins, C.B., J.F. Nock, and B.D. Whitaker. 2000. Responses of early, mid and late season apple cultivars to postharvest application of 1-methylcyclopropene (1-MCP) under air and controlled atmosphere storage conditions. Postharvest Biol. Technol. 19:17-23.

Yang, S. and N. Hoffman. 1984. Ethylene biosynthesis and its regulation in higher plants. Annu. Rev. Plant Physiol. 35:155-189. 